\title{
Penyuluhan Pangan Sehat Remaja Sebagai Upaya Menghadapi Perubahan Iklim
}

\author{
Mellia Harumi ${ }^{1}$, Alberta Rika Pratiwi ${ }^{2}$ \\ ${ }^{1,2}$ Teknologi Pangan, Unika Soegijapranata \\ ${ }^{1}$ mellia@unika.ac.id \\ 2pratiwi@unika.ac.id
}

\begin{abstract}
Abstrak: Pengabdian Masyarakat dalam rangka Hari Pangan Sedunia dilakukan bagi siswa-siswi SMK Pertanian Pembangunan (SPP) Kanisius Ambarawa, Jawa Tengah. Tujuan kegiatan ini adalah untuk memberikan pengetahuan tentang cara remaja bertindak cerdas dalam memilih makanan yang sehat di era perubahan iklim dan keadaan apa yang mempengaruhi perubahan iklim tersebut. Tujuan ini selaras dengan tema kegiatan yakni "Pangan yang Sehat di Era Perubahan Iklim". Ceramah dan diskusi tanya jawab menjadi alternatif metode yang dipilih pada kegiatan ini. Pelaksanaan kegiatan terdiri dari dua sesi topik. Sesi pertama dibuka oleh topik mengenai Perubahan Iklim dan Dampaknya bagi Masyarakat, yang kemudian dilanjutkan dengan sesi kedua mengenai asupan makanan dan pola hidup sehat di tengah perubahan iklim. Pemaparan topik dilanjutkan dengan diskusi dan tanya jawab yang melibatkan siswa-siswi kelas X, XI, dan XII serta guru SMK SPP Kanisisus Ambarawa. Hasil evaluasi memberikan pemaparan bahwa antusiasme dan ketertarikan siswa-siswi terhadap topik yang diambil sangat tinggi. Kegiatan serupa sangat penting untuk dilakukan kembali agar remaja mulai peduli akan pangan yang sehat di tengah perubahan iklim dan kondisi yang kurang kondusif akhirakhir ini. Melalui kegiatan ini diharapkan siswa SMK SPP mampu memahami keterkaitan perubahan iklim dan ketersediaaan bahan makanan sehat. Remaja juga semakin sadar bahwa konsumsi bahan makanan yang sehat tidak harus mahal. Ketersediaan bahan pangan di sekitar kita atau bahan pangan lokal dapat dijadikan alternatif memenuhi asupan gizi harian.
\end{abstract}

Kata kunci: iklim, pangan sehat, remaja

Abstract: The Community Service in order to World Food Day, carried out for students in SMK Pertanian Pembangunan (SPP) Kanisius Ambarawa, Jawa Tengah. This activity was aim to provide knowledge about how to be a smart teenager by choosing healthy food to encounter climate change and some conditions that effect the climate change. This aim analogue with the theme "Healthy Food in The Climate Change Era". Lecture series and followed by discussion became a good alternative method in this event. Lecture series consisted of two topic sessions. The first was opened by "Climate Change and It's Impact on Society", which was then followed by the second session on "Food Intake and Healthy Lifestyle Amid Climate Change". Discussion, as well as Question and Answer were followed by all students and teacher of SMK SPP Kanisius Ambarawa. Based on the evaluation method, student's enthusiasm and interest in that topics were high. Through this activity, hoped that students understand the connection between climate change and availability of healthy food. Local foods can be a good alternative to fulfill teenager's nutritional daily intake.

Keywords: Climate, Healthy Food, Teenager

\section{PENDAHULUAN}

Peningkatan temperatur bumi yang berpengaruh terhadap perubahan iklim menjadi perhatian serius bagi para peneliti di dunia. Perubahan iklim sering dikaitkan dengan tanggungjawab seluruh negara untuk membantu mengurangi emisi gas rumah kaca dan membatasi dampak yang 
merugikan. Gas-gas seperti uap air, karbon dioksida, metana dan nitrogen oksida turut berkontribusi terhadap munculnya Green House Effect (Kweku et al., 2017). Berdasarkan data yang diambil dari geocraft disebutkan bahwa penyumbang terbesar Green House Effect adalah uap air dan disusul oleh $\mathrm{CO}_{2}$.

Radiasi sinar Ultra Violet (UV) secara mudah dapat menembus dinding kaca dari Green House dan diadsorpsi oleh tumbuhan, sedangkan radiasi sinar Infrared (IR) sulit menembus dinding Green House dan cenderung terperangkap menyebabkan peningkatan panas di dalam Green House. Kondisi ini mengakibatkan penigkatan suhu bumi. Menurut National Academy of Sciences, temperatur permukaan bumi meningkat 1 derajat Farenheit dalam 100 tahun terakhir dan sebagian besar didominasi oleh adanya aktivitas manusia seperti kegiatan industri yang dapat meningkatkan $30 \%$ gas $\mathrm{CO}_{2}$ di atmosfer (Roul, Mishra dan Das., 2017).

Pertanian merupakan sektor penting pendukung ekonomi Indonesia dan menjadi suplai kebutuhan pokok masyarakat yang secara umum dipengaruhi oleh ilkim (Kuswanto et al., 2018). Perubahan iklim berpengaruh terhadap sektor pertanian, seperti pola tanam, waktu tanam, produksi, dan kualitas hasil. Kelembaban tanah dan variasi iklim yang sangat fluktuatif secara keseluruhan dapat mengancam keberhasilan produksi pangan. Penurunan intensitas curah hujan juga mengakibatkan penurunan hasil panen petani akibat peningkatan kekeringan (Hidayati dan Suryanto, 2015).

Beberapa kabupaten di Indonesia berada dalam keadaan rentan pangan. Tidak tersedianya bahan pangan mengakibatkan beberapa masyarakat mengalami gangguan kesehatan, kelaparan dan busung lapar (Sari dan Adi, 2016).

Mengatasi berbagai akibat yang mungkin ditimbulkan dari iklim yang tidak menentu, masyarakat Indonesia harus cerdas dalam memilih makanan. Bahan pangan yang dipilih dapat berasal dari bahan lokal dengan nilai ekonomis yang rendah namun memenuhi asupan gizi yang diperlukan tubuh.

Pangan lokal merupakan pangan yang diproduksi dan dikembangkan sesuai dengan potensi, sumberdaya, dan budaya wilayah setempat. Kondisi spesifik wilayah merupakan faktor yang mempengaruhi jenis, jumlah, dan kualitas produk pangan lokal. Beberapa tahun belakangan ini, ketersediaan beras sebagai bahan pangan utama mengalami penurunan (Utami dan Budiningsih, 2015). Keadaan ini menyebabkan dorongan pemerintah untuk mulai menggalakkan diversivikasi pangan dengan konsumsi bahan pangan lokal yang beragam seperti ubi, jagung, sagu, pisang, 
dan lain sebagainya sesuai potensi dan budaya lokal setempat. Hal ini tentunya dapat meningkatkan ketahanan pangan dan sebagai alternatif penurunan ketergantungan terhadap konsumsi beras.

Beberapa pangan lokal sering kali kurang diketahui oleh generasi masa kini. Di daerah Jawa Tengah misalnya, terdapat berbagai jenis olahan komoditas pangan lokal seperti ubi kayu, ubi jalar, ganyong, dan garut. Daerah pesisir seperti Bengkulu memiliki bahan baku produk utama tanaman pangan seperti sukun, singkong, serta sagu rumbia yang juga disusul oleh bahan baku produk tanaman perkebunan seperti kelapa dan gula kelapa (Marsigit, 2010). Berdasar penelitian yang dilakukan oleh Martianto, et al. (2009), terjadi perbedaan persentase atau penurunan konsumsi pangan lokal yang cenderung terjadi di wilayah perkotaan dibanding dengan daerah pedesaan.

SMK SPP merupakan Sekolah Pertanian, sehingga diharapkan siswa-siswi alumni sekolah ini mampu memahami perubahan iklim yang berdampak pada sistem pertanian dan kreatif dalam menyediakan bahan pangan yang tetap sehat. Saat ini mulai muncul petani milenial dengan berbagai teknologi yang mulai dikembangkan. Dengan adanya penanaman pengetahuan bahan pangan yang sehat serta asupan gizi remaja yang perlu untuk dipenuhi, maka generasi muda akan mejadi lebih peduli terhadap kesehatan. Bahan pangan yang sehat meliputi minimalisir penggunaan bahan berbasis kimia yang tidak hanya dapat membahayakan kesehatan namun juga permasalahan lingkungan. Bahan pangan yang sehat nantinya dapat menghasilkan olahan makanan yang sehat pula, sehingga dapat meningkatkan kesejahteraan masyarakat Indonesia.

\section{RUMUSAN MASALAH}

Berdasarkan latar belakang yang telah dikemukakan, kesadaran remaja untuk dapat peduli terhadap perubahan iklim yang terjadi menjadi sangat penting guna kelangsungan kesejahteraan Indonesia mendatang. Minimnya pengetahuan remaja tentang bahan pangan sehat dan pola makan yang sehat dengan nilai ekonomis rendah menjadi permasalahan yang perlu diselesaikan. Data penelitian terhadap 80 siswa-siswi SD di Denpasar tahun 2004 menunjukkan bahwa sebanyak $75 \%$ konsumsi energi anak-anak berasal dari jajanan dan hanya $25 \%$ nya saja yang berasal dari makanan pokok nasi, sayur, dan lauk pauk (Sukma dan Margawati, 2014). Hal ini juga menjadi faktor yang menyebabkan kegemukan di kalangan remaja. Remaja usia 13-15 tahun diketahui memiliki prevalensi berat badan gemuk sebanyak 2,9\% untuk laki-laki dan 2\% untuk perempuan berdasarkan data Riskesdas 
tahun 2010. Sedangkan masalah kurang gizi bagi remaja di umur yang sama mencapai $12,4 \%$ pada laki-laki dan $7,7 \%$ pada perempuan (Fauzi, 2021).

Dari rumusan masalah tersebut, program pengabdian masyarakat dilakukan dengan memperkenalkan remaja SMK SPP Kanisius, Ambarawa cara memilih pangan yang sehat di era perubahan iklim saat ini.

\section{METODE}

Pengabdian masyarakat dilakukan pada tanggal 8 November 2019 bertepatan dengan peringatan Hari Pangan Sedunia (HPS) yang bertempat di Aula SMK Pertanian Pembangunan (SPP) Kanisius Ambarawa Jawa Tengah dengan tema Pangan yang Sehat di Era Perubahan Iklim. Target peserta pengabdian masyarakt adalah seluruh siswa-siswi kelas X, XI, dan XII serta bapak dan ibu guru pendamping. Kegiatan ceramah terdiri dari 2 topik bahasan untuk setiap narasumber, yaitu Perubahan Iklim dan Dampaknya bagi Masyarakat, serta Keputusan Memilih Makanan. Setiap topik disampaikan dalam waktu 30 menit menggunakan sarana bentuk Power Point (PPT). Presentasi dilakukan di dalam kelas yang dilengkapi dengan sound system dan sarana presentasi LCD. Setelah dilakukan presentasi mengenai kedua topik tersebut, kemudian dilanjutkan dengan sesi diskusi selama 30 menit.
Pada tahap akhir dilakukan evaluasi terhadap kegiatan ceramah yang dilakukan. Evaluasi ini dilakukan oleh pihak narasumber dengan pihak SMK SPP Kanisius Ambarawa dan kemungkinan penyelenggaraan kegiatan yang serupa dikemudian hari.

\section{HASIL DAN PEMBAHASAN}

Pelaksanaan pengabdian masyarakat ini melibatkan siswa-siswi SMK SPP Kanisius Ambarawa Jawa Tengah yang terdiri dari kelas X, XI dan XII. Sesi pertama merupakan pemaparan mengenai Perubahan Iklim dan Dampaknya bagi Masyarakat. Pada kesempatan iini siswa dibekali tentang Global Warming dan apa saja aktivitas manusia yang berdampak bagi peningkatan suhu di bumi. Lebih jauh, para siswa diminta juga untuk paham mengenai dampak Global Warming bagi pertanian, kebutuhan pokok manusia dan kesehatan.

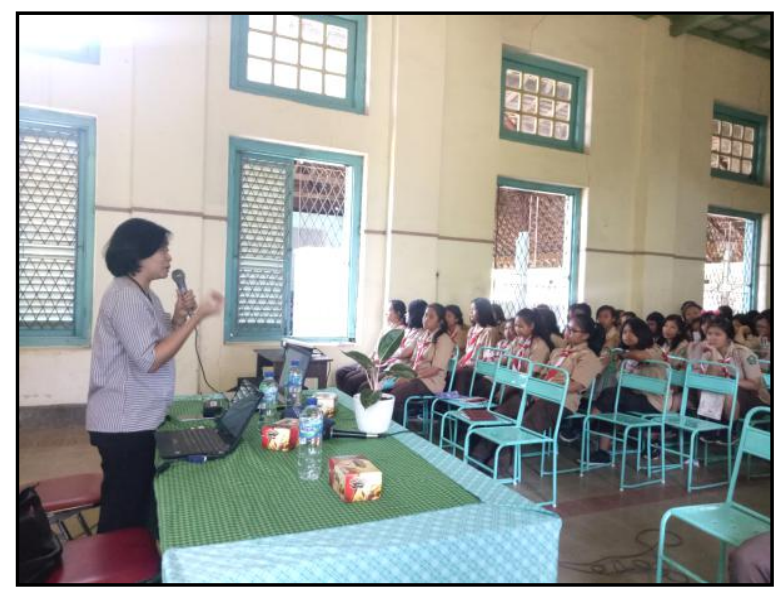

Gambar 1. Sesi 1 oleh ibu Alberta Rika Pratiwi

Sumber: Dokumentasi Pribadi 


Pentingnya menjaga kesehatan
melalui makanan sejak dini perlu
disampaikan kepada generasi muda
khususnya remaja SMA. Siswa-siswi
dibekali pengetahuan untuk dapat tetap sehat
di tengah perubahan iklim yang sangat
ekstrim melalui pemilihan makanan yang
tepat. Siswa-siswi diajak untuk dapat cerdas
dalam memilih makanan. Pemilihan bahan
pangan dapat didasarkan pada bahan pangan
lokal, bahan pangan yang tidak memiliki
nilai ekonomi yang tinggi, serta bahan
pangan tahan cuaca ekstrim.

Sesi kedua merupakan aplikasi tentang apa yang seharusnya bisa dilakukan untuk tetap sehat di era perubahan iklim saat ini melalui asupan makanan yang kita makan. Pada pendahuluan, siswa-siswi diberi pengetahuan mengenai pedoman gizi seimbang, bagaimana kebutuhan gizi yang harus kita cukupi setiap hari. Pemilihan makanan yang sehat tidak harus dengan harga yang mahal. Melalui ceramah ini, siswa-siswi diajak untuk dapat menghitung kebutuhan asupan per hari untuk laki-laki dan perempuan usia 16-18 tahun. Perhitungan secara sederhana untuk takaran porsi makan juga diedukasi agar siswa-siswi dapat memperkirakan banyaknya makanan yang diperlukan untuk setiap jenis makanan.

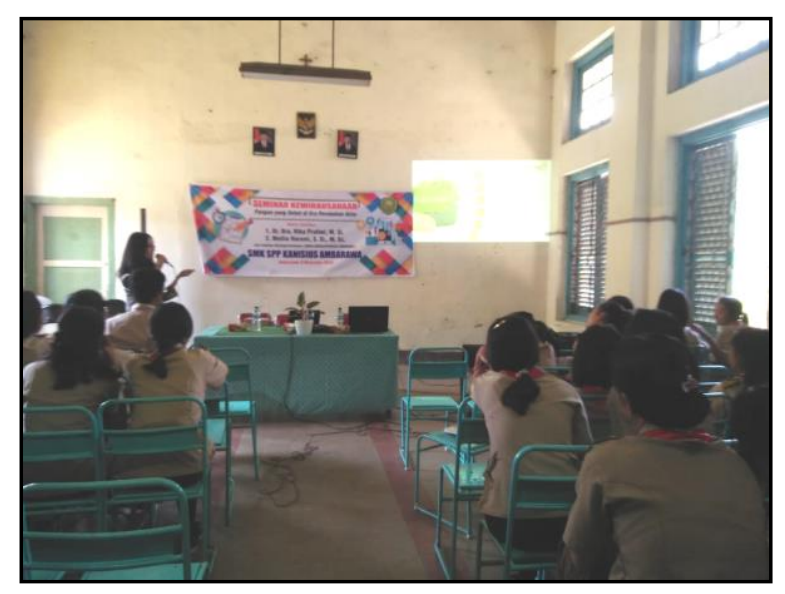

Gambar 2. Sesi 2 oleh ibu Mellia Harumi Sumber: Dokumentasi Pribadi

Melalui persentase Angka Kecukupan Gizi (AKG) remaja per hari, dilakukan perbandingan antara bahan pangan dengan nilai ekonomis yang rendah dan bahan pangan dengan harga yang relatif mahal. Dari setiap pemaparan, diperoleh pengertian bahwa dengan bahan pangan yang bernilai ekonomis rendah dan mudah didapat, diperoleh \%AKG yang memenuhi kebutuhan harian remaja. Melalui ceramah ini, diharapkan adanya pemahaman siswasiswi bahwa makanan yang sehat tidak perlu mahal, serta pentingnya menjaga kesehatan di tengah perubahan iklim.

Kegiatan ceramah ditutup dengan diskusi menarik dari pertanyaan para siswa terkait dua topik bahasan di atas. Pengabdian masyarakat terlaksana dengan lancar dan semua siswa memperhatikan serta aktif dalam bertanya kepada narasumber terkait topik yang sedang dibahas. 


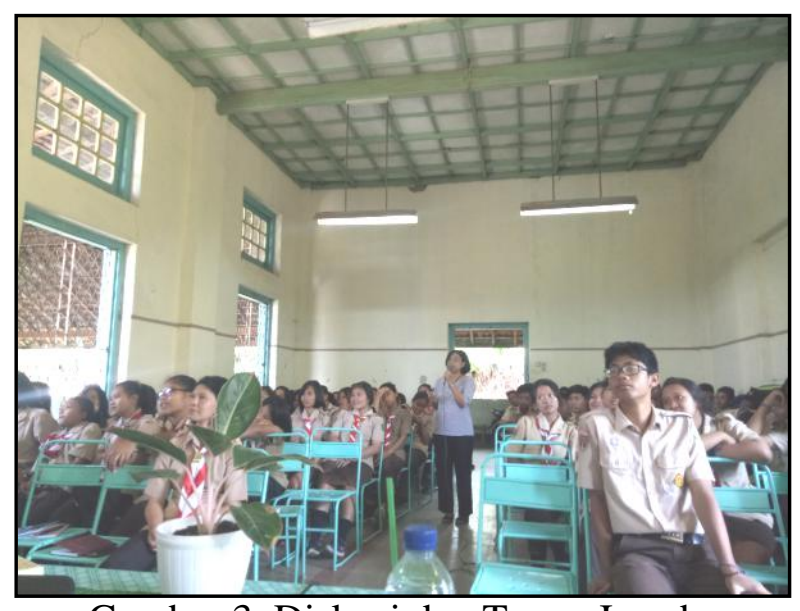

Gambar 3. Diskusi dan Tanya Jawab Sumber: Dokumentasi Pribadi

\section{PENUTUP}

Berdasarkan kegiatan pengabdian masyarakat yang telah dilakukan, dapat disimpulkan bahwa transfer pengetahuan kepada siswa-siswi remaja SMK SPP Ambarawa tercapai dengan baik. Hal ini nampak dari antusiasme peserta dalam mendengarkan setiap paparan yang disampaikan. Tidak hanya itu, banyak siswasiswi yang juga kritis dan mengajukan beberapa pertanyaan yang menandakan adanya antusiasme keingintahuan dari peserta. Harapannya, generasi muda menjadi lebih peduli terhadap alam dan kesehatan, serta dapat berpikir kreatif dalam menghadapi permasalahan yang melanda bumi ini. Kegiatan serupa disertai dengan inovasi cara penyampaian dan kuesioner pre dan post test saat kegiatan menjadi hal penting yang perlu diperhatikan untuk dapat mengukur peningkatan pengetahuan siswasiswi.

\section{UCAPAN TERIMAKASIH}

Terselenggaranya kegiatan

Pengabdian Masyarakat dalam rangka Hari Pangan Sedunia bagi siswa di SMK SPP Kanisius Ambarawa tidak lepas dari dukungan pihak SMK SPP Kanisius Ambarawa. Oleh karena itu, melalui kesempatan ini Tim Pengabdian Masyarakat mengucapkan terima kasih kepada Bapak Yakobus Sunaryo, S.P. selaku Kepala Sekolah SMK SPP Kanisius Ambarawa, Bapak Ibu Guru, serta para siswa yang telah memfasilitasi tempat dan mengkoordinir kegiatan sehingga kegiatan Pengabdian Masyarakat ini dapat berjalan dengan lancar.

\section{DAFTAR PUSTAKA}

Fauzi, C.A. (2012). Analisis Pengetahuan Dan Perilaku Gizi Seimbang Menurut Pesan Ke-6, 10, 11, 12 Dari Pedoman Umum Gizi Seimbang (PUGS) Pada Remaja. Jurnal Kesehatan Reproduksi, 3(2). 91-105.

Hidayati, I.N., dan Suryanto. (2015). Pengaruh Perubahan Iklim Terhadap Produksi Pertanian dan Strategi Adaptasi pada Lahan Rawan Kekeringan. Jurnal Ekonomi dan Studi Pembangunan, 16(1), 42-52.

Kuswanto, H., Salamah, M., Retnaningsih, S.M., dan Prasto, D.D. (2018). On The Impact of Climate Change to Agricultural Productivity in East Java. Journal of Physics, 979, 1-8.

Kweku, D.W., Bismark, O., Maxwell, A., Desmond, K.A., Danso, K.B., Mensah, E.A.O., Quachie, A.T., dan Adormaa, B.B. (2017). Greenhouse Effect: Greenhouse Gases and Their Impact on 
Global Warming. Journal of Scientific Research \& Reports, 17(6), 1-9.

Marsigit, W. (2010). Pengembangan Diversifikasi Produk Pangan Olahan Lokal Bengkulu untuk Menunjang Ketahanan Pangan Berkelanjutan. Agritech, 30(4), 256-264.

Martianto, D., Briawan, D., Ariani, M., Yuliani, N. (2009). Percepatan Diversifikasi Konsumsi Pangan Berbasis Pangan Lokal: Perspektif Pejabat Daerah Dan Strategi Pencapaiannya. Jurnal Gizi dan Pangan, 4(3), 123 - 131.

Roul, M.K., Mishra, R., dan Das, A. (2017). Impact of Increase in Greenhouse Gases on Global Warming and Its Remedies. Journal of Emerging Technologies and Innovative Research (JETIR), 4(12), 981-986.

Sari, S.M.W., dan Adi, A.C. (2016). Ketahanan Pangan dan Coping Strategy Rumah Tangga di Pulau Terisolir Gili Labak, Kabupaten Sumenep, Madura. Media Gizi Indonesia, 11(2), 153-159.

Sukma, D.C. dan Margawati, A. (2014). Hubungan Pengetahuan Dan Sikap Dalam Memilih Makanan Jajanan Dengan Obesitas Pada Remaja Di SMP Negeri 2 Brebes. Journal of Nutrition College, 3(4), 862-870.

Utami, P. dan Budiningsih, S. (2015). Potensi Dan Ketersediaan Bahan Pangan Lokal Sumber Karbohidrat Non Beras Di Kabupaten Banyumas. Jurnal Dinamika Ekonomi \& Bisnis, 12(2), 150-158. 